\title{
ANALISIS DE GASTOS PUBLICOS DISCRECIONALES: \\ LA POLITICA PRESUPUESTARIA \\ DE LA SEGUNDA REPUBLICA ESPAÑOLA
}

\author{
JUAN HERNANDEZ ANDREU \\ Universidad Complutense
}

\section{RESUMEN}

Este estudio tiene como objetivo ofrecer una interpretación de la politica preaupuestaria de los gobiemos republicanos. Para poder evaluar lo política económica-fiscal de la Segunda República se necesita comparar el déficit real del presupuesto con el déficit calculado, considerando el supuesto de una liquidación presupuestaria hipotética obtenida de unos ingresos públicos calculados en base a una renta hipotética, la real de un año determinado, que se atribuye a todo el periodo, y con la ratio ingresos/rente efectiva de cada año y una estructura hipotética de gastos públicos, calculados median. te la suatracción de determinados gastos públicos discrecionales. El déficit real de 1931 tiene como contrafactual la nivelación presupuestaria y su importe obedece a la política de fomento económico y social de los gobiernos republicanos.

\section{ABSTRACT}

This paper offers an interpretation of the budgetary policy of the Spanish governments during the Second Republic, 1931-1936. To judge the fiscal policy of this era, actual budget deficits are compared with estimated full employment deficits, that is, deficits that would have happened under conditions of high income levels, high government revenues, and relatively low expansionary expenditures. Contrary to traditional interpretations, such a comparison shows the 1931-1933 Spanish fiscal policy as relatively interventionist, and reveals a higher degree of social concern of the moderate cabinets of the Second Republic than is hitherto conceded.

Este estudio ${ }^{1}$ tiene como objetivo ofrecer una interpretación de la política presupuestaria de la Segunda República española. Quiero estudiar lo referente

Agradezco los comentarios a un primer borrador de este trabajo que hicieron los profesores James Foreman-Peck (Universidad de Oxford), Forrest Capie (City University of London), 
a la respuesta gubernamental ante el estancamiento de la economia española durante el decenio de 1930. Pienso que el tema es de la mayor importancia por las implicaciones económicas y sociales que supuso la implantación de un régimen democrático, por primera vez en España. El trabajo atiende: 1) a las tesis existentes sobre la política presupuestaria; 2) a las variables y mecanismos económicos que utilizo, y 3) a la valoración de la política presupuestaria de la República.

Quiero recordar sucintamente las tesis existentes sobre el tema que nos ocupa ${ }^{2}$. Raymond Carr ${ }^{3}$ destaca el carácter ortodoxo de las medidas fiscales de la Segunda República, si bien advierte que a pesar de sus principios económicos conservadores, los gobiernos republicanos hicieron notables esfuerzos para compaginar la nivelación presupuestaria con medidas destinadas a contrarrestar la depresión económica y social. Gabriel Jackson ${ }^{4}$ es más explícito en afirmaciones $\mathrm{y}$ argumentos que abundan en la misma evaluación que Carr hace de la política económica adoptada por los gobiernos de la Segunda República, destacando las mejoras establecidas en la eficiencia fiscal respecto al régimen anterior y en el contenido social introducido por el lado del gasto público, con limitaciones provenientes de la depresión económica.

La obra de Edward Malefakis's es rotundamente crítica, en cuanto a la gestión económica de 1931 a 1936. La reforma agraria, dice Malefakis, fracasó por insuficiencia de recursos financieros del Estado, via de causalidad que pone en palabras textuales del propio Manuel Azaña; y la insuficiencia fiscal vino motivada por el liberalismo de los gobiernos republicanos. La crítica se vuelve mordaz cuando razona que el impuesto sobre la renta, establecido en diciembre de 1932, sólo contemplaba a sujetos con un mínimo de 100.000 pesetas de renta anual, lo que suponia que iba a gravarse a sujetos con una renta superior en 80 veces a la renta per capita del pais.

La crítica de la actividad hacendistica de los gobiernos republicanos es detallada por Ramón Tamames ${ }^{6}$, quien advierte que los gobiernos republicanos aumentaron la presión fiscal respecto a la de los gobiernos de la Dictadura de Primo de Rivera. Sin embargo, señala Tamames que las previsiones recaudatorias, hechas por las autoridades hacendisticas, de 200 millones anuales, a obtenerse del nuevo Impuesto sobre la Renta, se vieron reducidas por el resul.

Michael Collins (Universidad de Leeds), Fernando Méndez Ibisate (Universidad Compluten. se) y Pedro Fraile (Universidad Carlos III).

2 He seleccionado los autores a tenor del enfoque que doy a este estudio.

3 R. Carr (1970), 587-589.

4 G. Jackson (1967), 74-75, 86-92 y 98-102.

SE. Malefakis (1972), 267.

6 R. Tamames (1975), 125-131. 
tado real de los 50 millones efectivamente recaudados; con todo, reconoce Tamames la atención del gobierno a gastar más en instrucción y pensiones, y a atender los compromisos de gastos derivados de la ejecución de obras públicas, y todo ello en un marco de depresión económica. Incluso llega a calificar el programa de obras públicas de Indalecio Prieto de «New Deal» a pequeña escala, valoración ya realizada, sin paliativos, ocho años antes por Gabriel Jackson ${ }^{7}$.

\section{GRAFICO 1}

Ingresos públicos (pesetas corrientes)

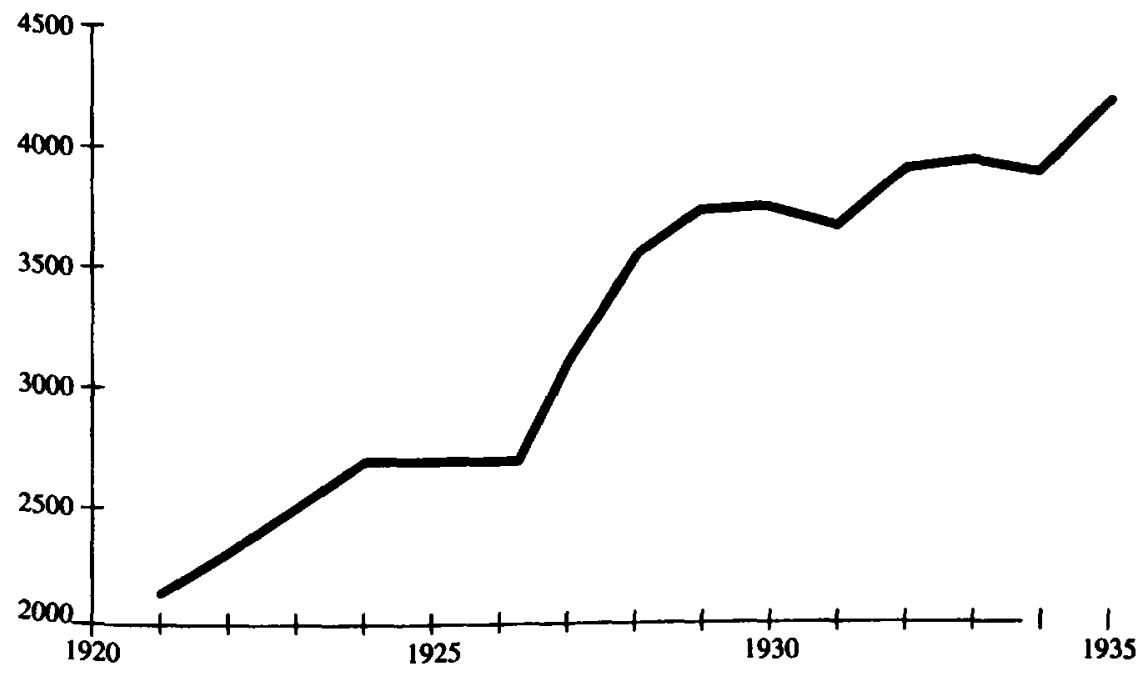

Pablo Martín Aceña y Francisco Comin ${ }^{8}$ centran fundamentalmente su estudio en comparar la tendencia de diversas variables monetarias y financietas, asi como la tasa de formación de capital proveniente del sector publico, para el periodo 1923.1930 respecto a los años que van de 1931 a 1935. Recientemente, Jordi Palafox ha publicado un libro que, en general, es descalificador de la gestión económica de la Segunda República. Para la valoración de la gestión presupuestaria recurre al viejo modelo de E. C. Brown, que no

\footnotetext{
G. Jackson (1967), 100.

P. Martín Aceña y F. Comin (1984).
} 
resuelve la imputación a los gastos discrecionales de los efectos en el saldo presupuestario 9 .

En definitiva, tenemos que, aunque existen también juicios comprensivos que atienden al alcance de la doctrina hacendistica imperante en aquella época, prevalecen hoy las valoraciones negativas sobre el esfuerzo económico anticiclico de la Segunda República. En cualquier caso, tomo la tesis de Raymond Carr como punto de partida de mi estudio, acudiendo a los instrumentos de teoria económica que permiten explicitar los supuestos teóricos contenidos en la hipótesis de Carr.

\section{GRAFICO 2 \\ Renta nacional (precios comientes)}

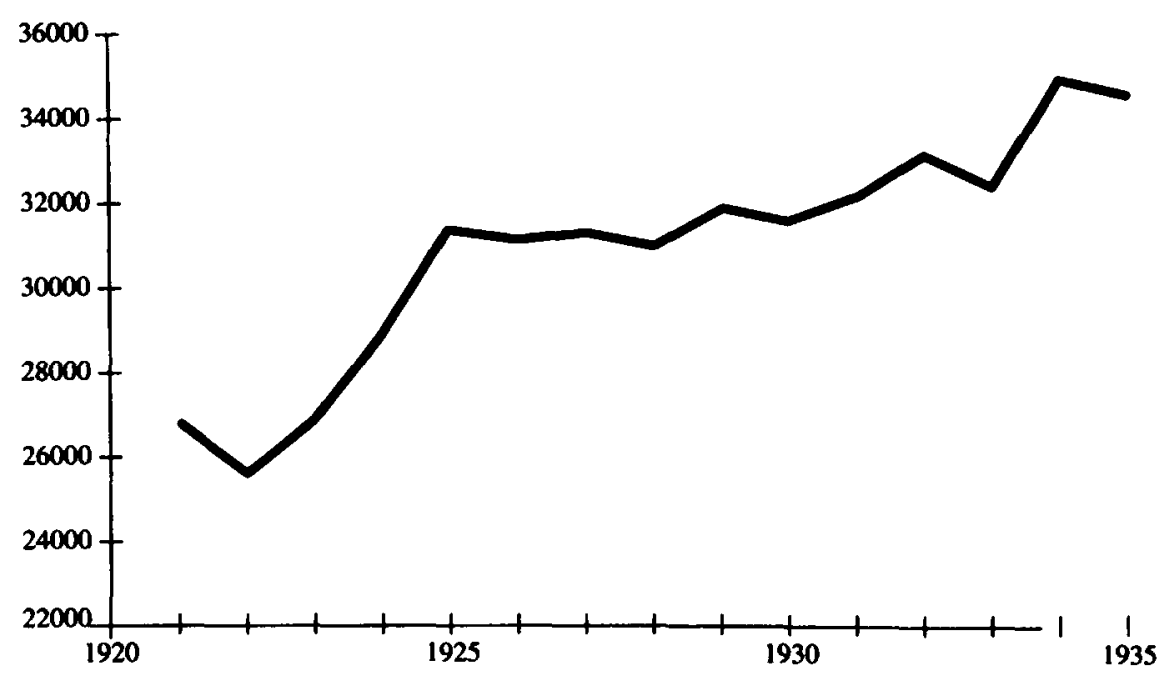

Mi investigación tiene los siguientes puntos analíticos básicos, que expongo precedidos de los correspondientes comentarios:

1) Las repercusiones de la tendencia económica, interna y exterior, así como las dificultades financieras y fiscales inherentes a todo cambio de régimen político es presumible que se manifestaron en la liquidación de los presu. puestos del Estado español de 1931 a 1935 . Pues bien, para medir esa reper-

\footnotetext{
9. Palafox (1991), 268-273. (Véase la crítica de L. C. Peppers al modelo de E. C. Brown.)
} 
cusión y poder analizar la relación entre el sistema económico y las finanzas públicas, en primer lugar calcularemos la elasticidad de los ingresos públicos respecto a la renta nacional, es decir, el efecto de las tasas de variación interanual de la renta nacional sobre los correspondientes porcentajes de cambio en los ingresos públicos.

2) En general, manteniéndose constantes los gastos públicos, una política de incremento de la presión fiscal es un freno para el incremento de la renta nacional. El gobierno tratará de expandir los gastos para aumentar, vía multiplicador, el PNB; pero también intentará incrementar la recaudación de impuestos para acercarse todo lo posible a la nivelación presupuestaria.

En el análisis de gastos públicos se distinguirá entre gastos no discrecionales y gastos discrecionales. Los primeros son aquellos en los que el margen de maniobra del gobierno es prácticamente nulo, es decir, aquellos gastos que son, digamos, inevitables. Por el contrario, los gastos discrecionales están vinculados a decisión política del gobierno, en función de la marcha de la economía expresada en la tendencia de la renta nacional.

Los gastos no discrecionales constituían la gran mayoria del volumen de gasto; pero ponderaremos el alcance de los gastos discrecionales, reveladores especificos de la política gubernamental, de su intervención intencionada en la tendencia de la economia. A este efecto, conviene tener presente también que el nuevo régimen heredó problemas financieros; así, los créditos pendientes de pago; las obras iniciadas y no terminadas; el empréstito de los bonos oro de tesoreria 6 por 100, libre de impuestos, para cancelar los créditos bancarios que bancos ingleses y americanos habian concedido al Tesoro y cuyo origen radicaba en la intervención de los cambios; y las «dobles» en moneda extranjera o préstamos externos que pesaban sobre el cambio internacional de la peseta y la balanza de pagos de España. Ello también debió contribuir a la insuficiencia fiscal acentuada por la crisis, y a que, por tanto, la liquidación de los presupuestos entre 1930 y 1935 fuera deficitaria.

Resultado de estos análisis, pienso puedo dar una interpretación, en el sentido que matizo al principio, de la política económica presupuestaria de los gobiernos republicanos, en términos más precisos que las ofrecidas por la historiografía tradicional, contribuyendo a explicar en términos económicos la buena intuición de los historiadores sociales. 


\section{INGRESOS PUBLICOS}

El análisis de la elasticidad entre ingresos públicos y renta nacional ${ }^{10}$ de 1921 a 1935 muestra que es a partir de 1930 cuando se da una elasticidad negativa entre las dos variables, salvo en el año 1932. En este año, el incremento de la renta está acompañado de incremento en la fiscalidad, en porcentajes muy similares. En 1931, un aumento del 1,3 por 100 de la renta está unido a una caída del 2,1 en los ingresos públicos. En 1933, al descenso de un 1,8 por 100 de la renta corresponde un alza de 1,4 por 100 de la recaudación, y a la caida de un 1,5 por 100 de la renta en 1935 sigue un aumento de ingresos públicos del 1,6 por 100. En cambio, en 1934 el aumento de la renta nacional en un 7,9 por 100 fue acompañado de una caida del 1,5 por 100 en la recaudación. De estos datos se desprende que hubo mejor gestión recaudatoria durante 1932-1933 que en 1934 (gráficos 1, 2 y 3).

\section{GRAFICO 3 \\ Elasticidad ingreso público/renta nacional}

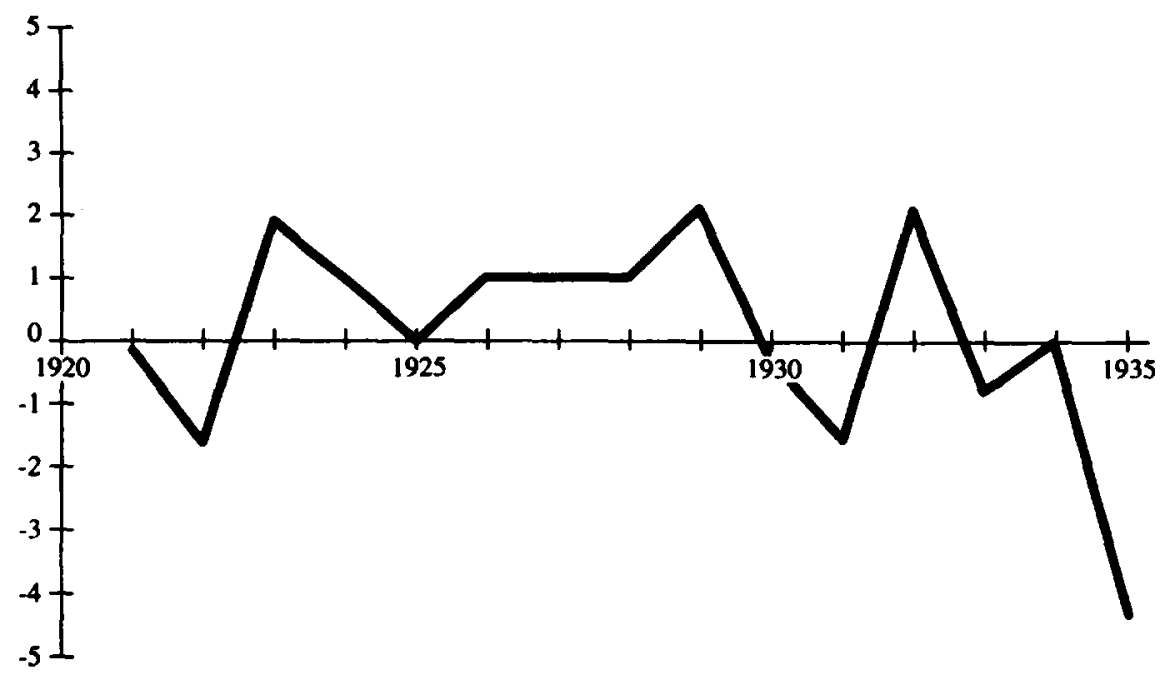

FuENTE: Anexo 1.

10 Se calcula la elasticidad punto. Si Y = renta nacional; dy = incremento de la renta nacional respecto al año anterior, $\mathrm{T}=$ ingresos públicos; $\mathrm{dT}=$ incremento de los ingresos públicos respecto al año anterior, la elasticidad entre ingresos públicos y renta nacional $=\mathrm{dT} / \mathrm{T} / \mathrm{dY} / \mathrm{Y}$. 
El resultado fiscal positivo de 1932 podria relacionarse con el aumento de tarifas que dispusiera el ministro de Hacienda Jaime Carner. Con todo, no aumentó sensiblemente la presión fiscal, que se mantuvo constante, a efectos prácticos, durante el decenio de 1930 (véase anexo I); sólo en el año 1933, la ratio $\mathrm{T} / \mathrm{Y}$ muestra unas décimas por encima de los otros ejercicios, pero lo considero insignificante. Indicativo de ello es la correlación entre los ingresos públicos y la renta nacional, cuyo coeficiente de correlación es de 0,80 .

\section{GASTOS PUBLICOS}

En cuanto a los gastos públicos, el desglose de las principales partidas, entre 1930 y 1935, se expone en el cuadro $1^{11}$. Este método aplicado al decenio de 1930 se inspira en trabajos de E. C. Brown, E. M. Gramlich, W. H. Oakland, W. Lewis, L. C. Peppers, Alan Blinder y Robert Solow, T. Dernburg, Frank de Leeuw y T. Holloway, P. Muller y Robert Price, V. Tanzi, R. Eisner y P. Pieper, M. Blejer y Chu Ke-young, M. I. Blejer y A. Chesty, Heller y Blanchard. El estudio de Brown es el primer trabajo cuantitativo de politica fiscal que contiene estimaciones implícitas de superávit de pleno empleo. Los ingresos fiscales potenciales se deducen de multiplicar los impuestos reales por la ratio de PNB potencial respecto al real. Este procedimiento de proporcionalidad implica la elasticidad unitaria de los impuestos totales con respecto al PNB y produce serias distorsiones cuando se aplica a la estructura impositiva que no es una unidad elástica. Según Peppers, un fallo del superávit de pleno empleo es considerar los efectos estimuladores del tamaño absoluto del presupuesto. En este sentido, Gramlich construyó un superávit de pleno empleo ponderado, que incorpora pesos diferentes para impuestos, transferencias y gastos del gobierno. Por su parte, Oakland señala que el impacto expansivo de cualquier acción fiscal está mejor medido por sus efectos sobre el nivel de renta real (inicial), no sobre el nivel de renta de pleno empleo. La técnica de ponderación de los diversos componentes fiscales es rechazada por Peppers, por razones prácticas más que por argumentos teóricos. Asimismo W. Lewis reconoce esto y concluye que el superávit de pleno empleo sin ponderar es una via razonable para evaluar las políticas fiscales del pasado. Frente a la vía del superávit de pleno empleo y a la de superávit real (inicial), Peppers ofrece una tercera via que califica de agrado de estabilización incorporadaw, que clarifica

\footnotetext{
"League of Nations (1927-1936).
} 
haciendo referencia a dos supuestos. En periodos de cambio estructural, durante los cuales se modifican los estabilizadores internos, ocurre que los cambios en el superávit de pleno empleo ofrecen signos engañosos acerca de los efectos cíclicos reales de la política fiscal; en este caso son mayores los cambios en el superávit real (inicial). En un periodo en el que los estabilizadores permanecen constantes, el superávit de pleno empleo da resultados significativos ${ }^{12}$.

\section{CUADRO 1}

Principales departamentos y servicios que incrementan gastos, 1931-1935 (en millones de pesetas)

\begin{tabular}{|c|c|c|c|c|}
\hline & 1930 & 1931 & 1934 & 1935 \\
\hline Servicio de la deuda pública .. & 885,2 & 896,7 & $1.008,2$ & 939,8 \\
\hline Clases pasivas $\ldots \ldots \ldots \ldots \ldots \ldots \ldots \ldots \ldots \ldots \ldots \ldots \ldots \ldots \ldots \ldots \ldots \ldots$ & 149,6 & 192,2 & 314,8 & 317,1 \\
\hline 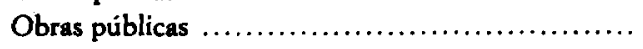 & 464,9 & 503,1 & 700,7 & 607,1 \\
\hline Instrucción pública .... & 187,5 & 203,9 & 312,0 & 326,9 \\
\hline 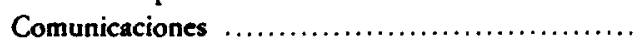 & - & 96,1 & 157,1 & 155,1 \\
\hline 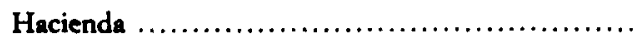 & 45,2 & 54,9 & 99,6 & 86,1 \\
\hline
\end{tabular}

FUENTE: League of Nations, Memorandum on Public Finance, 1928-1935, Ginebra, 1936.

\section{LA FUNCION DE SUPERAVIT PRESUPUESTARIO}

La función de superávit presupuestario, que relaciona el superávit presupuestario (ingresos públicos menos gastos públicos) con la renta nacional se representa en el gráfico 4. Los cambios endógenos en el saldo presupuestario del gobierno debidos a cambios en la renta nacional y no a la política presupuestaria se observan en los movimientos de una efunción de superávit» dada.

12 E. C. Brown (1956), E. M. Gramlich (1966), W. H. Oakland (1969), W. Lewis (1968), L. C. Peppers (1973). Una problemática derivada de la relación entre déficit y ciclo económico, con diversos intentos no exentos de dificultad para poder discernir los efectos ciclicos de otros provenientes de otras causas: Alan Blinder y R. Solow (1974), T. Dernburg (1975), Frank de Leeuw y Pieper (1988), M. Blejer y Chu Ke-Young (1988), M. I. Blejer y A. Chesty (1991), Heller y otros (1986) y O. Blanchard (1986). 
Los cambios en el saldo presupuestario debidos a cambios inducidos por la política gubernamental del gasto o en los tipos impositivos y no en los niveles de renta nacional se muestran por cambios en la efunción de superávit». Tales cambios indican una liquidación presupuestaria diferente para cada nivel de renta nacional.

\section{GRAFICO 4}

Función de superávit presupuestario

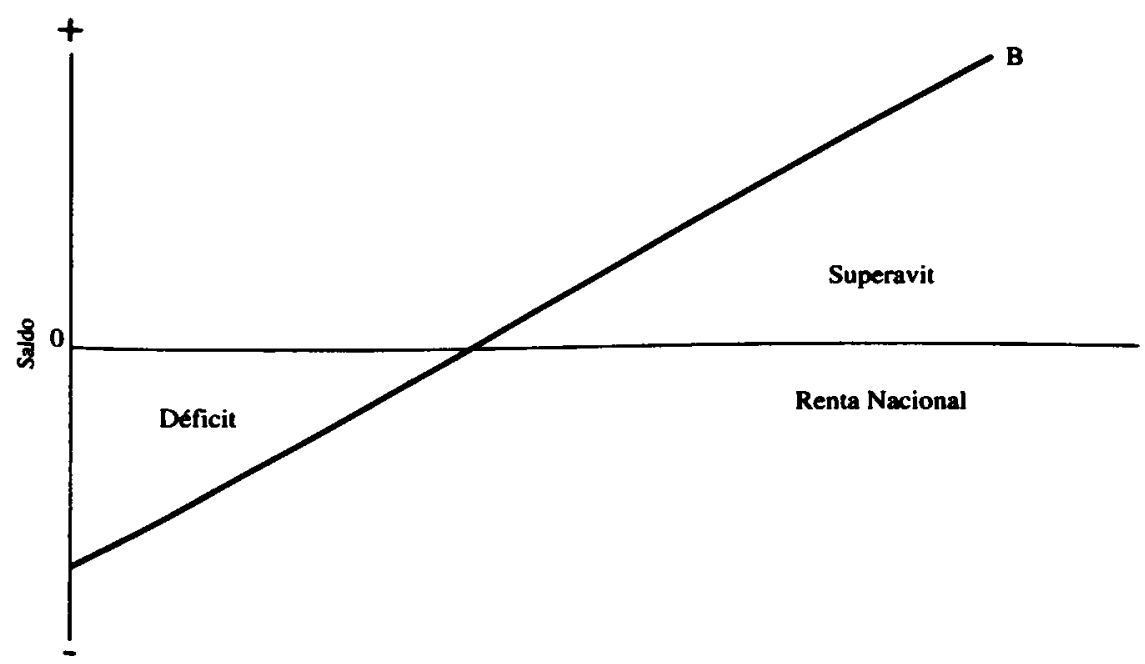

Si se toma un nivel de renta nacional como constante a lo largo de un periodo considerado, se observa que los cambios durante esos años en el saldo presupuestario son causados por modificaciones de tipo político sobre la función de superávit. La renta nacional generalmente más utilizada como base es la srenta nacional de alto empleo* y el saldo calculado se llama el usuperávit de alto empleo» (HES). Esto es, una estimación de los ingresos públicos menos los gastos públicos, no por su importe real, sino por el que se alcanzaría de darse una potencial renta nacional. La denominación debería ser superávit de pleno empleo, pero el volumen de paro que acompaña a una renta potencial haría embarazoso utilizar la expresión superávit de pleno empleo, y Lipsey y Steiner prefieren el calificativo de superávit de alto empleo ${ }^{13}$.

\footnotetext{
"Lipsey y Steiner (1984), 599, nota 5.
} 
Los cambios en el superávit de alto empleo (HES) son un índice de los cambios en la estructura de la política fiscal. El superávit de alto empleo es la medida adecuada más simple para valorar las modificaciones de la estructura fiscal. Como dije antes, cambios en la renta nacional causan cambios en el «superávit» corriente mediante el movimiento de la economía a lo largo de su «función de superávit»; cambios en la estructura de la política fiscal modifican la «función de superávit». La función de superávit presupuestario expresa la diferencia entre los ingresos públicos y los gastos públicos en cada nivel de renta nacional. En el gráfico 4 la función expresa que los déficit están asociados con bajos niveles de renta nacional y los superávit con altos niveles de renta.

\section{GRAFICO 5}

\section{Cambios en el superávit corriente}

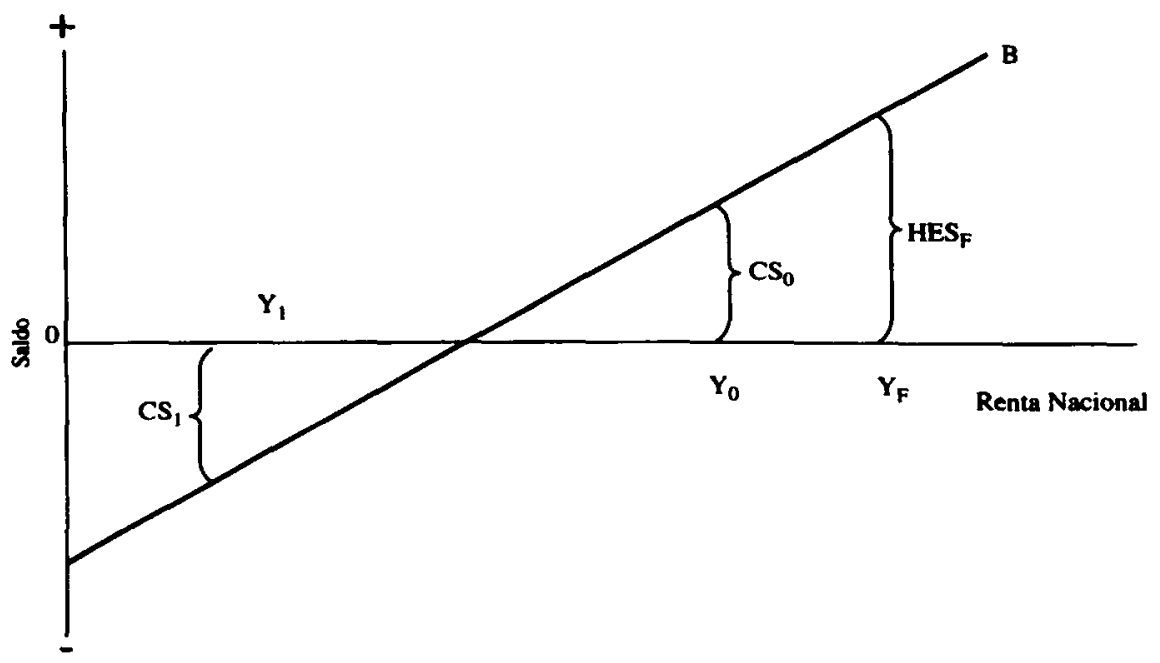

En el gráfico 5 vemos que una caída en la renta nacional de $Y_{0}$ a $Y_{1}$ causa que el presupuesto vaya de un superávit corriente $\mathrm{CS}_{0}$ a un déficit corriente $\mathrm{CS}_{1}$, sin cambio en el gasto público o en los tipos impositivos; esto es, la estructura de la política fiscal permanece inalterada. La posición constante de la política fiscal se recoge correctamente, estableciendo constante el superávit de alto empleo, HES.

En el gráfico 6 hay un cambio contractivo en la posición de la política fiscal: un corte en el gasto público y/o un incremento en el tipo impositivo desplaza la función de superávit de $B_{0}$ a $B_{1}$. Ahora existe un más ancho superávit 


\section{GRAFICO 6}

\section{Cambios en el superávit de alto empleo}

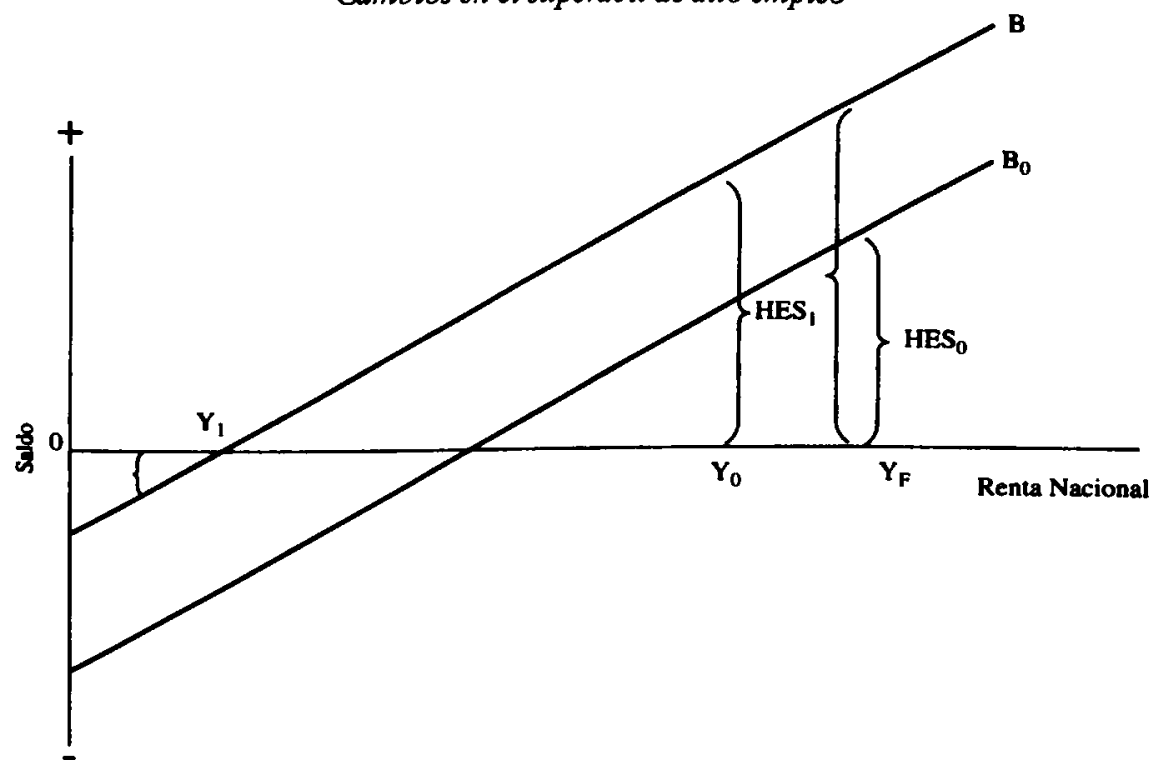

presupuestario en cada nivel de renta nacional. Este cambio es correctamente captado por el aumento del superávit de alto empleo, de $\mathrm{HES}_{\mathrm{o}}$ a $\mathrm{HES}_{1}$.

Advierto que si la renta nacional habia caído de $Y_{0}$ a $Y_{1}$, al mismo tiempo que la función de superávit se desplazó de $B_{o}$ a $B_{1}$, el saldo corriente habría ido de superávit a déficit a pesar del aumento en el superávit de alto empleo. Esto ilustra los efectos engañosos de juzgar cambios en la estructura de la política fiscal, desde cambios en el superávit corriente.

Entiendo que los saldos presupuestarios son función: 1) de la renta nacional, sobre la que incide la correspondiente presión fiscal y que en mi modelo considero constante, a efectos operativos, y se generan, asi, los ingresos públicos, y 2) de la política gubernamental, que puede generar variaciones de los volúmenes de gastos y/o de los tipos impositivos, que se aplican a las figuras tributarias (budgetary stance).

De manera que si considero el nivel de renta constante, a través de la renta de alto empleo para todo un período considerado, puedo medir la evolución del saldo presupuestario en función de los cambios en la política de gastos públicos y/o de cambios en las tasas impositivas; es decir, puedo valorar las repercusiones de una política de gastos públicos sobre el saldo presupuestario, ya que, como dije, entiendo constante también la presión fiscal, es decir, la 
ratio $\mathrm{T} / \mathrm{Y}$ (ingresos públicos/renta nacional). En España esta ratio cambia poco durante los años 1921-1927, y menos cambia aún, según dije antes, en los años de 1928 a 1935.

Er. definitiva, para poder evaluar la política de gastos gubernamentales de la Segunda República se precisa comparar, año a año, la tendencia del saldo presupuestario auténtico con la evolución correspondiente del saldo obtenido considerando el supuesto de una liquidación presupuestaria hipotética. Este saldo hipotético se calcula por la diferencia entre:

1) Los ingresos públicos obtenidos por la simulación de que existiera una misma renta para todos los años; eligiéndose como renta nacional base o constante para todo el período, la del año que realmente fue más alta. Sobre la cifra de esta renta nacional se aplica la ratio $\mathrm{T} / \mathrm{Y}$ efectiva de cada año en cuestión.

2) Los gastos públicos hipotéticos, calculados, año a año, mediante la substracción de determinados gastos públicos discrecionales.

La aplicación de aquel método a la política presupuestaria de la Segunda República, para valorarla en comparación a la politica presupuestaria de la Dictadura de Primo de Rivera, permite calcular una evolución hipotética del déficit presupuestario entre 1923 y 1935 según las siguientes mediciones (las series de cifras estän en anexo I):

1) Cálculo de los ingresos: Se ha tomado la $Y$ de 1934 como la renta nacional de «alto empleow constante para todo el periodo y se ha aplicado sobre ella la presión fiscal (T/Y), ingresos püblicos/renta nacional, la real, de cada año. De manera que considero la misma presión fiscal en los ingresos reales y en los hipotéticos, lo cual asegura y explicita la causalidad de los gastos discrecionales para explicar la diferencia entre el saldo real y el hipotético. La Y de $1934^{14}$ es la más alta, en términos absolutos, de todo el período. Y se obtiene asi la serie de ingresos públicos hipotéticos.

2) Cálculos de los gastos públicos:

a) Para 1923-1930 se ha restado de los gastos discrecionales (pensiones más obras públicas más instrucción) la media de los mismos para 1921-1923,

\footnotetext{
14 La elección de la renta nacional de un año es punto controvertido (De Leeuw y Holloway, 1985), 232; la opinión predominante es que debe elegirse la renta nacional más alta, porque esta menos afectada por el ciclo depresivo (Mario I. Blejer y Adrianne Cheasty, 1991), 1654. Hay autores que proponen tomar como renta nacional básica el axerage output.
} 
eliminando asi los gastos públicos discrecionales de los años anteriores a la etapa que estudiamos, y la cifra resultante, para cada año de la serie, se ha restado de la serie de gastos públicos totales (GP), desde 1923 a 1930.

b) Para 1930-1935 se ha restado de los gastos discrecionales la media de los mismos para 1928-1930, y la cifra resultante, para cada año de la serie, se ha restado de la serie de gastos públicos totales (GP), de 1931 a 1935. La serie está en anexo 1 con los títulos GPD* y los déficit aparecen en el mismo anexo bajo el título GPF.

La elección de los gastos públicos referidos como discrecionales se fundamenta no sólo en la apreciación empírica, ya que son los que más aumentan durante la II República, como señalé en cuadro 1 y que asi lo aprecia el informe de la Sociedad de Naciones, sino también en mis cálculos expresados en el cuadro 2.

\section{CUADRO 2}

Matriz de coeficientes de correlación 1920-1935

\begin{tabular}{|c|c|c|c|c|c|c|}
\hline & & $G$ & $G-T$ & $G P$ & $G P D$ & GPND \\
\hline$Y \ldots \ldots$ & & 1 & .279 & .470 & .785 & .444 \\
\hline $\mathrm{Y}(+1) \ldots \ldots \ldots \ldots$ & & - & .508 & .594 & .747 & .311 \\
\hline \multicolumn{7}{|c|}{$\begin{array}{l}\Sigma \mathrm{GPD}=11.127,2 \\
\Sigma \mathrm{GP}=51.101,0\end{array} \mid \Sigma \mathrm{GPD} / \Sigma \mathrm{GP} \times 100=21,77 \%$} \\
\hline \multicolumn{7}{|c|}{ 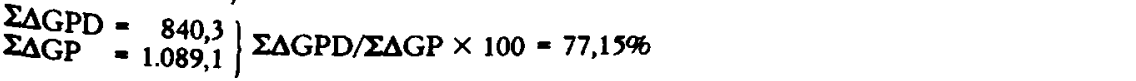 } \\
\hline
\end{tabular}

Veamos el cuadro 2 para fundamentar la elección de los gatos discrecionales. Si bien el porcentaje de los gastos públicos discrecionales sobre los gastos públicos totales entre 1920 y 1935 es sólo del 21,7 por 100, el porcentaje de incremento de los gastos públicos discrecionales sobre el aumento de los gastos públicos totales es del 77,15 por 100 . Además es también expresiva la matriz de coeficientes de correlación para el mismo periodo; la correlación entre GPD (gastos públicos discrecionales) e $Y$, asi como respecto a $Y(+1)$, aplicando un decalaje de un año, valorando la influencia de los GPD sobre la $Y(+1)$, de un año para otro, la correlación es significativa; los coeficientes son 0,785 y 0,747 , respectivamente. No así son altamente correlativos el déficit público, los 
gastos públicos totales o los gastos públicos no discrecionales respecto a $\mathrm{Y} o$ $Y(+1)$. Por tanto, queda probada la corrección de elegir pensiones, obras públicas e instrucción, como capítulo de GPD. (Véase ecuaciones y gráficos que acompañan al cuadro 2.)

La aplicación del método que he seguido, que permite medir las repercusiones en la liquidación presupuestaria de la ejecución de los gastos discrecionales, del modo razonado y expuesto en los términos referidos, arroja una liquidación presupuestaria entre 1920 y 1935 diferente a la real. (Véase gráfico 7.)

Tanto durante la Dictadura como durante la República vemos una política presupuestaria real, discrecional del gobierno, importante, pero el margen de actuación, en términos de recursos, de la República es mucho menor, a partir

\section{GRAFICO 7}

Déficit reales y déficit de alto empleo en España, 1922/23-1935

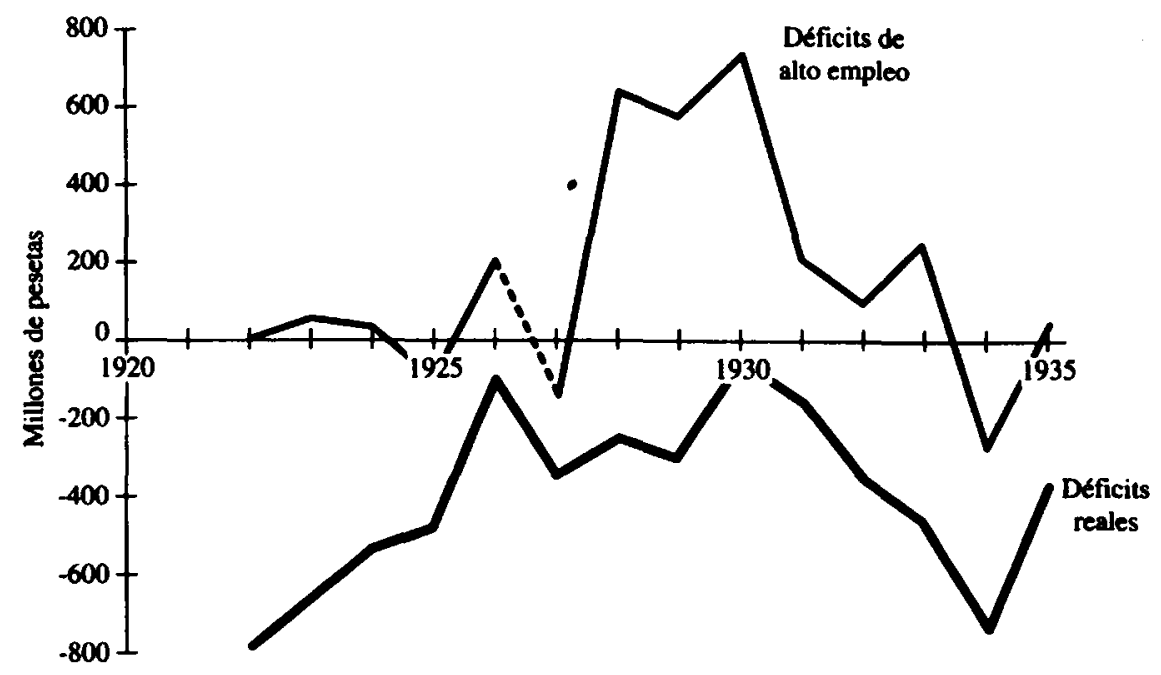

FUENTE: Anexo 1.

Cálculo de los ingresos: Se ha tomado la $Y$ de 1934 como la $Y$ de alto empleo para todo el periodo y se ha aplicado la presión fiscal (T/Y) de cada año.

Cálculo de los gastos: a) Para 1923-1930 se ha restado de los gastos discrecionales (Pensiones +O.P. Inst.) la media de los mismos para 1921.23, y la cifra resultante se ha restado de los gastos públicos desde 1923 a 1930 . b) Para $1930-1935$ se ha restado de los gastos discrecionales la media de los mismos para 1928-1930, y la cifra resultante se ha restado de la serie de gastos públicos de 1931 a 1935 . 
de 1931, la diferencia entre la liquidación hipotética y la real disminuye ostensiblemente.

El déficit real de 1931, 1932 y 1933 tiene como saldo hipotético la nivelación presupuestaria y su importe obedece a la política de fomento económico y social de los gobiernos republicanos; por otro lado, el nivel de déficit real de estos años es análogo al de los presupuestos de la Dictadura; en cambio, entre 1927 y 1930 el saldo hipotético arroja un superávit que es el doble del déficit real de estos años.

Para el año 1934, la diferencia entre el déficit de presupuesto de alto empleo y el déficit real señala la parte de déficit atribuible a la política del gobierno para incrementar la renta nacional; el déficit hipotético que persiste, algo menos de la mitad del déficit real, tiene un origen estructural, que desaparece en 1935 .

\section{CONCLUSION}

¿Qué muestran estos datos? Que la política de la Dictadura no fue deliberadamente ortodoxa, entendiendo por ortodoxia específicamente la nivelación del presupuesto; y la politica presupuestaria de la República no fue pasiva ante los problemas económicos y sociales derivados de la coyuntura económica y que su esfuerzo de gasto fue mayor que durante la Dictadura de Primo de Rivera.

Es importante señalar que a pesar de las cargas financieras heredadas por la Segunda República, que mencioné al principio, si nos atenemos a un contexto de gastos no discrecionales y de ingresos de presupuesto de alto empleo, los gobiernos republicanos, salvo en 1934, no habrian tenido déficit. También mido el alcance de la política presupuestaria desde 1931 para propiciar, mediante gastos discrecionales, mejoras sociales y educativas y otros destinados a medidas de fomento, lo cual confirma parte de la tesis de Carr, que hubo una política presupuestaria expansiva por parte de los gobiernos republicanos.

\section{BIBLIOGRAFIA}

Alcaide Inchaustn, J. (1976): «Una revisión urgente de la serie de renta nacional española en el siglo XX*, en Datos Básicos para la Historia Financiera de España 1850-1975, Instituto de Estudios Fiscales, vol. I, 1127-1150. 
Blanchard, O. (1990): «Suggestions for a new set of fiscal indicators», OECD Economics and Statistics Department Working Papers, núm. 79, abril.

Blejer, M. I., y Chesty, A. (1991): «The Measurement of Fiscal Deficits: Analytical and Methodological Issues», Joumal of Economic Literature, vol. XXIX, 4, 1644-1678.

BLEJER, M., y KE-Young (1988): Measurement of Fiscal impact: Methodological issues, Washington, D.C.: Intenational Monetary Fund, 32-47.

Blinder, A., y Solow, R. (1974): «Analytical Foundations of Fiscal Policy», en The economics of Public finance, ed. Blinder $\mathrm{y}$ otros, Washington, D.C.: Brookings Institution, 3.115.

BroAdBERRY, S. N. (1986): The British Economy between the Wars, Blackevelh, Oxford.

Brown, E. C. (1956): «Fiscal Policy in the Thirties: A Reappraisal», The American Economic Review, 857.879.

Calle, R. (1981): La Hacienda en la II Repriblica Española, ed. Instituto de Estudios Fiscales, Madrid, 2 vols.

CARR, R. (1970): España 1808-1939, ed. Ariel, Barcelona.

Comin, F. (1989): Hacienda y Economia en la España Contemporánea, 2 vols., Instituto de Estudios Fiscales, Madrid.

Dernburg, T. (1975): «Fiscal Analysis in the Federal Republic of Germany: The Cyclically Neutral Budget», Intermational Monetary Fund Staff Paper, noviembre, 22 (3), 825-57.

Eisner, R, y Pieper, P. (1988): «Deficits, Monetary Policy and Real Economic Activityw, The Economics of Public Debt, eds. Kenneth, Arrow y Boskin, New York, Mac Millan, 3-38.

Leeuw, F. DE, y Holloway, T. (1983): «Cyclical Adjustment of the Federal Budget and Federal Debts, Surv. Curr. Bus., diciembre, 25-40.

Gramlich, E. M., «The Behavior and Adecuacy of the United States Federal Budget 1952-1964», Yale Economics Essays, 6, núm. 1, 99-159.

Heller y otros (1986): aA Review of the Fiscal Impulse Measure», Occasional Paper núm. 44, Washington, D.C., International Monetary Fund, mayo.

Hernandez Andreu, J. (1980): Depresión Económica en España, 1925-1934, ed. Instituto de Estudios Fiscales, Madrid.

- (1986): España y la crisis de 1929, ed. Espasa-Calpe, Madrid.

JACKsON, G. (1967): La República española y la guema civil, 1931-1939, ed. Grijalbo, México.

League Of Nations, Memorandum on Public Finance 1922-1926, Ginebra, 1927.

-, Memorandum on Public Finance 1926-1928, Ginebra, 1929.

—., Public Finance 1928-1935, Spain, Ginebra, 1936.

LEWIS, Jr. W. (1968): Budget Concepts for Economic Analysis, Washington, D.C., Brookings Institution.

Muller, P., y Price, R. (1984): «Structural Budget Deficits and Fiscal stance», OECD, Economics and Statistics Department, Working Papers, july (15).

OAkLand, W. H. (1969): «Budgetary Measures of Fiscal Performancew, Soutbern Economic Joumah 35, abril.

Lipsey, R. G.; Steiner, P. O., y Purvis, D. D. (1984): Economics, Harper Row, Pub., Nueva York.

MALEFAKIS, E. (1972): Reforma agraria y revolución campesina en la España del siglo xx, Ariel, Barcelona. 
Martin Aceña, P. (1984): La política monetaria en España 1919-1935, ed. Instituto de Estudios Fiscales, Madrid.

(1985): La cantidad de dinero en España 1900-1935, ed. Banco de España, Servicio de Estudios, Madrid.

- y ComfN, F. (1984): «La politica monetaria y fiscal durante la Dictadura y la Segunda República», Papeles de Economía, núm. 20, 236-261.

Melguizo, A. (1979): «El presupuesto de Calvo Sotelo», Cuademos económicos de ICE, núm. 10, 301.442.

Payne, S. G. (1987): El Régimen de Franco, 1936-1975, ed. Alianza, Madrid.

PALAFoX, J. (1991): Atraso económico y democracia. La segunda República y la economia española, 1892-1936, ed. Crítica, Madrid.

Peppers, L. C. (1973): «Full-Employment Surplus Analysis and Structural Change: 1930sw, Explorations in Economic History, 197-210.

Resúmenes Estadísticos de Recaudación y Pagos y Liquidación Provisional del Presupuesto 1923/1924-1930.

RIU, D. (1935): «La liquidación de los Presupuestos del Estado y esbozo de un plan de política financiera», Economía Española, núm. 29, 1-68.

TAmames, R. (1975): La República-La era de Franco, ed. Alianza, Madrid.

TANZI, V. (1982): «Fiscal Disequilibrium in Developing Countries», World Development, diciembre, 1069-82.

THOMAs, H. (1976): La guerra civil española, ed. Grijalbo, Madrid, 2 vols.

Tortella, G. (1983): «Los problemas económicos de la segunda Repüblica», Revista de Estudios Políticos, núm. 31-32, 121-135.

TURNER, P. (1989): «Wealth effects and fiscal policy in the 1930s», Documento de Trabajo, Scbool of Business and Economic Studies. University of Leeds.

VV. VV.(1986): La Hacienda Pública en la Dictadura, 1923-1930, ed. Instituto de Estudios Fiscales, Madrid. 
ANEXO 1

\begin{tabular}{|c|c|c|c|c|c|c|c|}
\hline & 1920 & $1921 / 22$ & $1922 / 23$ & $1923 / 24$ & $1924 / 25$ & $1925 / 26$ & $1926 / 11$ \\
\hline$\ldots \ldots \ldots \ldots \ldots$ & - & 2131,9 & 2296,8 & 2508,8 & 2682,8 & 2696,1 & 1437,3 \\
\hline$\ldots \ldots$ & - & 85,9 & 164,9 & 212 & 174 & 13,3 & -1259 \\
\hline $\mathrm{dT} / \mathrm{T} \ldots \ldots \ldots \ldots \ldots \ldots$ & - & 4,19 & 7,735 & 9,23 & 6,936 & 0,496 & $-46,7$ \\
\hline $\mathbf{Y} \ldots \ldots \ldots \ldots \ldots \ldots \ldots$ & - & 26925 & 25660 & 26916 & 28927 & 31350 & 31102 \\
\hline $\mathrm{dY} / \mathbf{Y} \ldots \ldots \ldots \ldots \ldots \ldots \ldots$ & - & -18 & $-4,7$ & 4,89 & 7,47 & 8,38 & $-0,8$ \\
\hline $\mathrm{dT} / \mathrm{T} / \mathrm{dY} / \mathrm{Y} \ldots \ldots \ldots \ldots \ldots$ & - & $-0,23$ & $-1,65$ & 1,886 & 0,928 & 0,059 & 59,02 \\
\hline $\mathbf{T} / \mathbf{Y} \ldots \ldots \ldots \ldots \ldots \ldots \ldots$ & - & 7,92 & 8,95 & 9,32 & 9,27 & 8,6 & 4,62 \\
\hline GP $\ldots \ldots \ldots \ldots \ldots \ldots \ldots \ldots$ & 2984 & 3468,3 & 3135,8 & 3175,6 & 3231,4 & 3188,1 & 1561.7 \\
\hline T/GP $\ldots \ldots \ldots \ldots \ldots \ldots$ & -1336 & -1336 & -839 & $-666,8$ & $-548,6$ & -492 & $-124,4$ \\
\hline T.GP $/ Y \ldots \ldots \ldots \ldots \ldots$ & 4,07 & 4,96 & 3,27 & 2,48 & 1,9 & 1,57 & 0,4 \\
\hline GPD $\ldots \ldots \ldots \ldots \ldots \ldots \ldots$ & - & 411,8 & 379 & 433,2 & 482 & 545,5 & 223,2 \\
\hline GPD $\times 100 \ldots \ldots \ldots \ldots \ldots$ & - & 100 & 92,03 & 105,2 & 117 & 132,5 & 54,2 \\
\hline GPND,$\ldots \ldots \ldots \ldots \ldots \ldots$ & - & 3056,5 & 2756,8 & 2742,4 & 2749,4 & 2642,6 & 1338,5 \\
\hline GPND $\times 100 \ldots \ldots \ldots \ldots \ldots$ & - & 100 & 90,19 & 89,72 & 89,95 & 86,46 & 43,79 \\
\hline$G P \times 100 \ldots \ldots \ldots \ldots \ldots$ & - & 100 & 90,41 & 91,56 & 93,17 & 91,92 & 45,03 \\
\hline$(T-G P) \times 100 \ldots \ldots \ldots \ldots \ldots$ & - & $-100,03$ & $-62,799$ & $-49,91$ & $-41,063$ & $-36,826$ & $-9,3114$ \\
\hline TF $\ldots \ldots \ldots \ldots \ldots \ldots \ldots$ & - & 2762,721 & 3123,147 & 3252,231 & 3236,017 & 3000,712 & 1612,445 \\
\hline $\mathrm{GPD}^{*} \ldots \ldots \ldots \ldots \ldots \ldots \ldots$ & - & - & 3,8 & -29 & 25 & 74 & 137,5 \\
\hline GPF-GP-GPD * $\ldots \ldots \ldots \ldots$ & - & - & 3132 & 3204,6 & 3206,4 & 3114,1 & 1424,2 \\
\hline TF-GPF $\ldots \ldots \ldots \ldots \ldots \ldots$ & - & - & $-8,85325$ & 47,631 & 29,616787 & $-113,388$ & 188,24523 \\
\hline
\end{tabular}

$T=$ Ingresos Püblicos.

$\mathrm{dT}=$ Incremento de Ingresos Públicos respecto al año anterior.

$Y=$ Renta Nacional.

dY - Incremento de Renta Nacional respecto al año anterior.

GP = Gastos públicos.

GPD - Gastos Públicos Discrecionales.

GPND = Gastos Públicos No Discrecionales.

TF - Ingresos Públicos hipotéticos.

GPD * - Gastos Públicos Discrecionales, excluido el valor medio de los correspondientes a los dos años anteriores a la etapa histórica que se valora.

FUENTE: Memorandum League of Nations. Alcaide.

La Sociedad de Naciones utilizaba los datos de resümenes estadisticos publicados por la Intervención General de Tesoreria y Contabilidad, que me han permitido comprobar la validez de los datos del Memorandum. Los Memoranda tienen la ventaja de uso por sus agrupaciones sistemáticas de los diversos renglones. 


\begin{tabular}{rrrrrrrrr}
\multicolumn{1}{r}{1927} & 1928 & 1929 & 1930 & 1931 & 1932 & 1933 & 1934 & 1935 \\
\hline 3014,6 & 3524,1 & 3724,4 & 3735,5 & 3656,7 & 3886,4 & 3942,4 & 3883,4 & 4139 \\
1577 & 509,5 & 200,3 & 11,1 & $-78,8$ & 229,7 & 56 & -59 & 255 \\
109,7 & 16,9 & 5.684 & 0,298 & $-2,11$ & 6,282 & 1,441 & $-1,5$ & 6,582 \\
31244 & 31002 & 31844 & 31503 & 31922 & 32921 & 32324 & 34892 & 34358 \\
0,46 & $-0,8$ & 2,72 & $-1,1$ & 1,33 & 3,13 & $-1,8$ & 7,94 & $-1,5$ \\
240,4 & $-21,8$ & 2,093 & $-0,28$ & $-1,59$ & 2,007 & $-0,79$ & $-0,19$ & $-4,3$ \\
9,65 & 11,4 & 11,7 & 11,9 & 11.5 & 11,8 & 12,2 & 11,1 & 12 \\
3383,5 & 3792 & 4037,9 & 3795,2 & 3853,2 & 4287,5 & 4447,7 & 4654,1 & 4557,4 \\
$-368,9$ & $-267,9$ & $-313,5$ & $-59,7$ & $-196,5$ & $-401,1$ & $-505,3$ & $-770,7$ & $-418,4$ \\
1,18 & 0,86 & 0,98 & 0,19 & 0,62 & 1,22 & 1,56 & 2,21 & 1,22 \\
602 & 871,9 & 921,7 & 802,1 & 899,2 & 1099 & 1289 & 1328 & 1252 \\
146,2 & 211,7 & 223,8 & 194,8 & 218,4 & 266,8 & 313.1 & 322.4 & 304 \\
2781,5 & 2920,1 & 3116,2 & 2993,1 & 2954 & 3188,8 & 3158,4 & 3326,6 & 3305,3 \\
91 & 95,54 & 102 & 97,93 & 96,65 & 104,3 & 103,3 & 108,8 & 108,1 \\
97,55 & 109,3 & 116,4 & 109,4 & 111,1 & 123,6 & 128,2 & 134,2 & 131,4 \\
$-27,612$ & $-20,052$ & $-23,466$ & $-4,4686$ & $-14,708$ & $-30,022$ & $-37,822$ & $-57,687$ & $-31,317$ \\
3366,58 & 3966,289 & 4080,887 & 4137,354 & 3996,917 & 4119,081 & 4255,606 & 3883,4 & 4203,329 \\
$-184,8$ & 463,9 & 513,7 & 394,1 & 34 & 233,8 & 423,8 & 462,8 & 386,8 \\
3568,3 & 3328,1 & 3524,2 & 3401,1 & 3819,2 & 4053,7 & 4023,9 & 4191,3 & 4170,6 \\
$-201,7201$ & 638,18918 & 556,68697 & 736,25409 & 177,71675 & 65,381097 & 231,70639 & $-307,9$ & 32,729297 \\
\hline
\end{tabular}

